\section{Mechanical analysis of a portal steel frame when subjected to a post-earthquake fire}

\author{
Mohammed Redha Merouani, ${ }^{1}$ \\ Belkacem Lamri, ${ }^{1}$ Abdelhak Kada, ${ }^{1}$ \\ Paulo Piloto ${ }^{2}$
}

${ }^{1}$ Department of Civil Engineering,

Faculty of Civil Engineering and

Architecture, Hassiba Benbouali

University of Chlef, Algeria;

${ }^{2}$ Department of Applied Mechanics,

Polytechnic Institute of Bragança,

Bragança, Portugal

\begin{abstract}
Although current design code can manage the separate action of a fire or an earthquake, which causes a significant threat to the human life and to the integrity of the structures, the dual effect of a PostEarthquake Fire (PEF) stands as a major hassle to designers and rescuers alike. Algerian seismic design code, RPA99v2003, with no exception does not consider the possibility of a subsequent fire after an earthquake, whose effect can significantly weaken the steel frame and destroy its fire protection. This paper presents the evaluation of the fire resistance for a two-storey steel portal frame, damaged by an earthquake simulated through spectrum response of Chlef, scaled three in the Algerian Seismic Code. First, the design of the steel structure considers seismic actions by a static nonlinear analysis. Second, it is followed by a fire analysis using an ISO834 standard fire model, considering that the structure is partially damaged. The finite element simulation and numerical analysis of the structure in post-earthquake fire condition yield the bilinear capacity curve at ambient temperature and the variation of local and global displacement at high temperature. A final comparison of the damaged (PEF) and undamaged (FIRE) frames subjected to the different fire scenarios is done.
\end{abstract}

\section{Introduction}

Fire or earthquake pose a significant threat to the human life, and can cause an enormous damage to the structures, moreover the dual effect of a Post-Earthquake Fire (PEF) is a major hassle to designers and rescuers alike. The experiments carried out by Petrina $(2016)^{1}$ show that post-earthquake fire produces serious damage to the structural elements after their load resistance has been altered by a seismic action.
Extensive research to study the behavior of unprotected and protected steel structures, 2,3 has been done, and yet there is still a great need for the understanding of the behaviour of structures damaged by earthquakes and exposed to fire.

The most PEF studies begin with a seismic study of the structure by applying the gravity loads, followed by a fire analysis, on the frames already damaged by the earthquake.

The work done by Zaharia et al. (2009) ${ }^{4}$ illustrates PEF resistance through two different cases of unprotected steel frames damaged by an earthquake on two seismic regions with moderate and severe ground motions using a Pushover analysis according to the Eurocode $8 .{ }^{5}$ It was confirmed that the fire resistance of the structures considering their deformed state under earthquake is lower than the structures that do not have any early deformation prior to the application of the fire.

Behnam and Ronagh $(2015)^{6}$ conducted sequential analysis based on FEMA $356,{ }^{7}$ to investigate the PEF resistance for two 5storey portal frames, designed to meet the Life Safety (LS) and Immediate Occupancy (IO) level of performance, followed by a fire analysis, using both the ISO834 model and the natural fire model. The results for two fire scenarios, on the $1^{\text {st }}$ and $5^{\text {th }}$ floor, indicate that the majority of fires analysis resulted in the local collapse while all PEF analyses resulted in the global collapse.

Designers, when considering Algerian seismic rule (RPA99v2003), ${ }^{8}$ ignore the possibility of a post-earthquake fire, whose effect can lead to the dramatic collapse of the structures. ${ }^{9}$ This paper presents the evaluation of the fire resistance for a two-storey steel portal frame, damaged by an earthquake simulated through spectrum response of Chlef scaled three in the Algerian Seismic Code. ${ }^{8}$ First the design of the steel structure considers seismic actions by a static nonlinear analysis. Second a fire analysis using an ISO834 standard fire model is followed, considering that the structure is partially damaged. The finite element simulation and numerical analysis of the structure in post-earthquake fire condition yield the bilinear capacity curve at ambient temperature and the variation of local and global displacement at high temperature. A final comparison of the damaged (PEF) and undamaged (FIRE) frames subjected to the different fire scenarios is presented.

\section{Materials and Methods}

Three step analysis procedure based on the framework was performed. The first
Correspondence: Belkacem Lamri, Department of Civil Engineering, Faculty of Civil Engineering and Architecture, Hassiba Benbouali University of Chlef, Pole of Ouled Fares, BP. 78C, Chlef, Algeria.

Tel. +213.561337071 - Fax: +213.27727235

E-mail: b.lamri@univ-chlef.dz

Key words: RPA99v2003; Post-earthquake fire; Nonlinear analysis; Fire resistance; ISO834.

Contributions: MRM carried out the simulations, analyzed the data, contributed with the writing of the manuscript; BL conceived and designed the project, contributed in the numerical models, analyzed the results, wrote the manuscript; AK conceived and designed the project, contributed with the steel structure fire and post-earthquake fire analyses, analyzed the results, helped with the writing of the manuscript; PGP contributed in the numerical models, reviewed and provided critical feedback on the manuscript, contributed to the data interpretation.

Conflict of interest: the authors declare no potential conflict of interest.

Funding: this work was funded by the National Research Fund from the DGRSDT/MESRS, Algeria.

Conference presentation: part of this paper was presented at the $5^{\text {th }}$ Iberian-LatinAmerican Congress on Fire Safety (CILASCI $5^{\text {th }}$ Congress), 2019, July 15-17, Porto, Portugal.

Received for publication: 4 September 2019 Accepted for publication: 23 September 2019.

This work is licensed under a Creative Commons Attribution 4.0 License (by-nc 4.0).

${ }^{\circ}$ Copyright: the Author(s), 2019

Licensee PAGEPress, Italy

Fire Research 2019; 3:76

doi:10.4081/fire.2019.76

stage of loading is the application of gravity loads, which are assumed to be static and uniform followed by a pushover analysis, while the displacement demand under the corresponding seismic event was determined using the $\mathrm{N} 2$ method according to the Eurocode 8..$^{5}$ According to the N2 method, the seismic response spectrum is determined for a system with an equivalent single degree of freedom (SDOF). Pushover curve have been obtained for multi-degree of freedom systems (MDOF) and it is therefore necessary to determine the simplified force-displacement characteristic for the equivalent SDOF systems using the elastic response spectrum of the city of Chlef (Seismic Zone III with soft soil S3 and con- 
trol period $\mathrm{T}_{\mathrm{C}}=0.5 \mathrm{sec}$ ) given by Figure $1 .{ }^{8}$

The structure is pushed with a monotonically increasing lateral load to a different desired performance level. In this study four performance levels were considered, first performance point obtained by the N2 method, and then three other performance points depended of the storey drifts.

For the seismic analysis, a multi-linear stress-strain curve is used (Figure 2) for the European steel profiles of S235 steel grade.

Finally, the PEF is applied in the form of fire load to the damaged structure under uniform temperature, simulated by the standard ISO 834 to understand the mechanical behavior of solid unrestrained steel Ibeams. ${ }^{10}$

A comparative study is done with an identical unprotected portal frame considered undamaged by the earthquake (FIRE), with the same duration of fire exposure $(60$ minutes).

For the simulation of the behavior of the steel frame, the finite element model based on structural analysis procedure in ANSYS, ${ }^{11}$ was developed, using a quadratic three-node finite beam element (Beam189), with six degrees of freedom at each node. The element is based on Timoshenko beam theory, which includes shear-deformation effects.

\section{Eurocode temperature on portal steel sections}

In this study, the standard ISO834 fire was applied on all four faces of the internal columns, the exterior side of external columns is not exposed to fire. Meanwhile, only three sides of beams are exposed to fire, because it is assumed that the top side is well protected by the concrete slab.

The standard ISO834 fire model is given by the following temperature-time relationship, ${ }^{12}$ where $t$ represents the time in minutes (Eq. 1):

$\theta_{g}=20+345 \log _{10}(8 t+1)$

Eq. 1

The increase of temperature leads to the reduction of the mechanical properties such as the Yield stress $f_{y}$ and the Young's modulus E. The Reduction factors for the stressstrain relationship of steel at elevated temperatures, used for the analysis, are computed according to Eurocode1.12 Consequently,

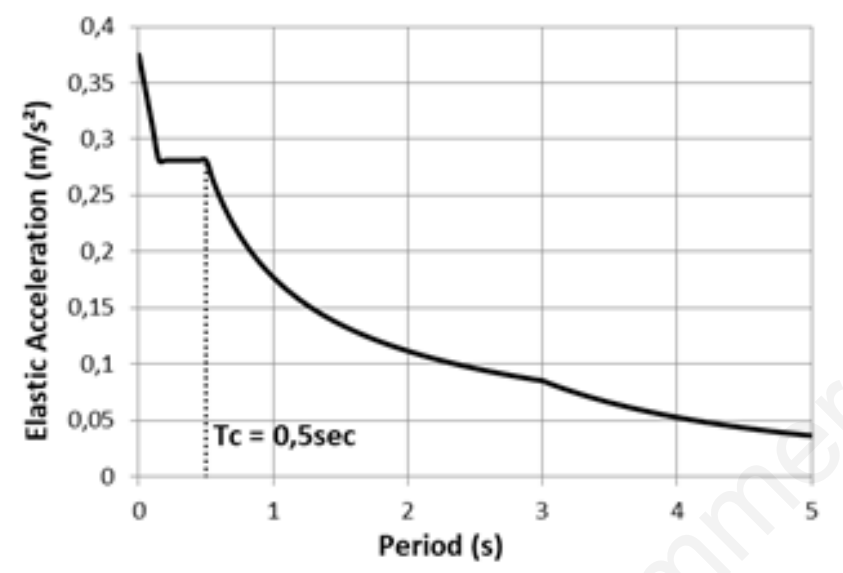

Figure 1. Elastic response spectrum for the city of Chlef.

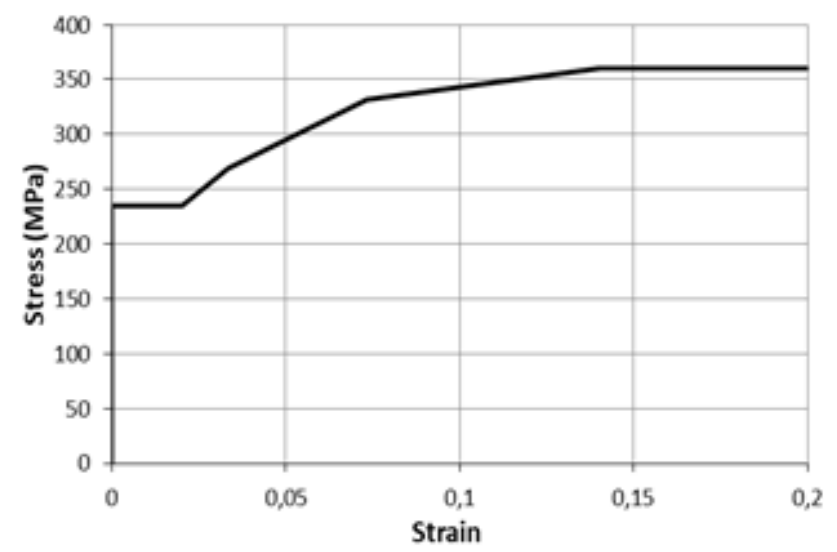

Figure 2. Stress-Strain Curve at ambient temperature (earthquake).

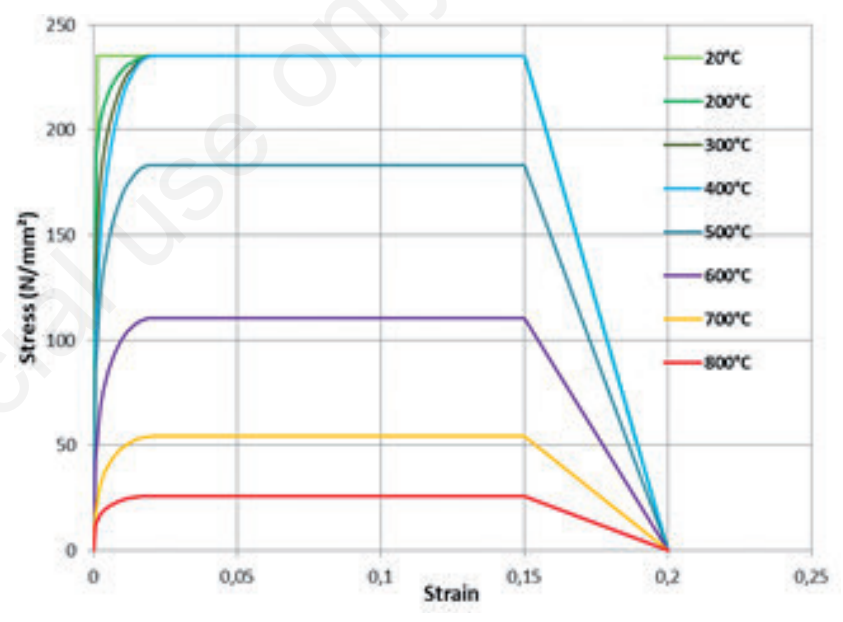

Figure 3. Stress-Strain at elevated temperature (S235).

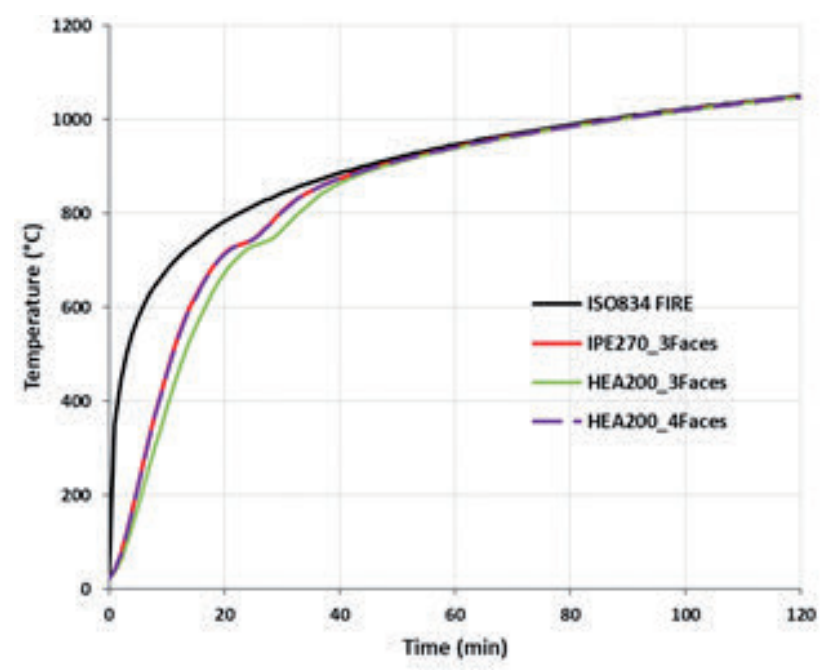

Figure 4. Time-Temperature curve for the columns and beams. 
the stress Strain curve for the steel grade S235 at high temperature is established and given in Figure 3.

Figure 4 shows the time temperature variation for ISO834 fire and the temperature for the IPE270 and HEA200 cross sections under ISO834 fire, considering a uniform temperature distribution, the temperature increase $\Delta \theta_{\mathrm{a}, \mathrm{t}}$ for the unprotected steel member during a time interval $\Delta \mathrm{t}$ should be obtained from (Eq. 2): $:^{13}$

$\Delta \theta_{a, t}=k_{s h} \cdot\left(\frac{1}{C_{a} \cdot \rho_{a}}\right) \cdot\left(\frac{A_{m}}{V}\right) h_{n e t} \Delta$

Where: $k_{\mathrm{sh}}$ is the correction factor for the shadow effect, $A_{m} / V$ is the section factor for unprotected steel members $\left[\mathrm{m}^{-1}\right], \mathrm{C}_{\mathrm{a}}$ is the specific heat of steel $[\mathrm{J} / \mathrm{kgK}], \rho_{\mathrm{a}}$ is the unit mass of steel $\left[\mathrm{kg} / \mathrm{m}^{3}\right], \dot{h}_{n e t}$ is the design value of the net heat flux per unit area $\left[\mathrm{W} / \mathrm{m}^{2}\right], \Delta \mathrm{t}$ is the time step [seconds]

\section{Validation of the numerical model}

For the validation of the structural analysis model a single bay portal frame is taken from Chandra et al. (2016). ${ }^{14}$ The frame is of steel grade S235 having span and height of $3.5 \mathrm{~m}$ each. The dead and live load considered in the analysis are 13.5 $\mathrm{kN} / \mathrm{m}$ and $6 \mathrm{kN} / \mathrm{m}$ respectively. The simulations are done using the beam finite element model, Beam189, from ANSYS software. ${ }^{11}$

The frame is statically analysed initially with gravity loads only. Subsequently it is pushed to the target displacement corresponding to the desired performance levels. For the validation study two performance levels considered were - Operational $(\mathrm{O})$ : $\delta / \mathrm{h}=1.0 \%$; and Life Safe (LS): $\delta / \mathrm{h}=2.0 \%$.

The result for the pushover analysis is presented in terms of capacity curve (Base Shear vs Storey drift) as shown in Figure 5 , and reveals a good agreement with the twodimensional numerical study conducted by Chandra et al. ${ }^{14}$

In the second part of this validation, the ISO 834 fire was applied on all four faces of the beams and columns, considering a uniform temperature on all the cross sections.

The purpose of the fire structural analysis is to verify the fire resistance rating of the damaged structure and subsequently determine the effects of earthquake damage on the fire resistance rating.

The evolution of the vertical displacement, at half span of the beam, in terms of fire exposure duration of the damaged frame for the two performance levels, Operational (Drift 1\%) and Life Safe (Drift $2 \%$ ) is given in Figure 6A.

The variation of normalized fire resistance that is the ratio of the PEF fire resistance corresponding to a given performance level (drift) to the fire resistance of undam-

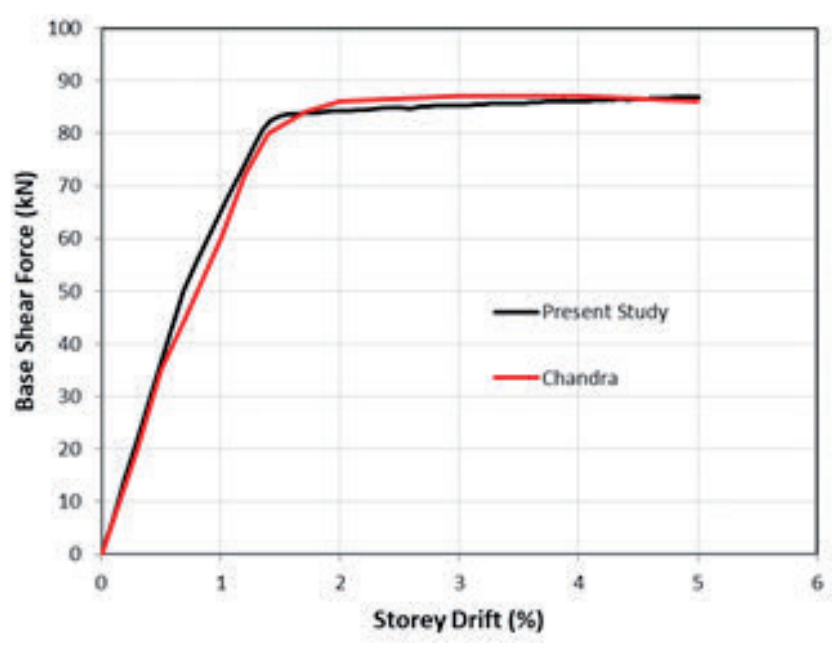

Figure 5. Pushover Curves: present study vs Chandra et al.'s study.14.
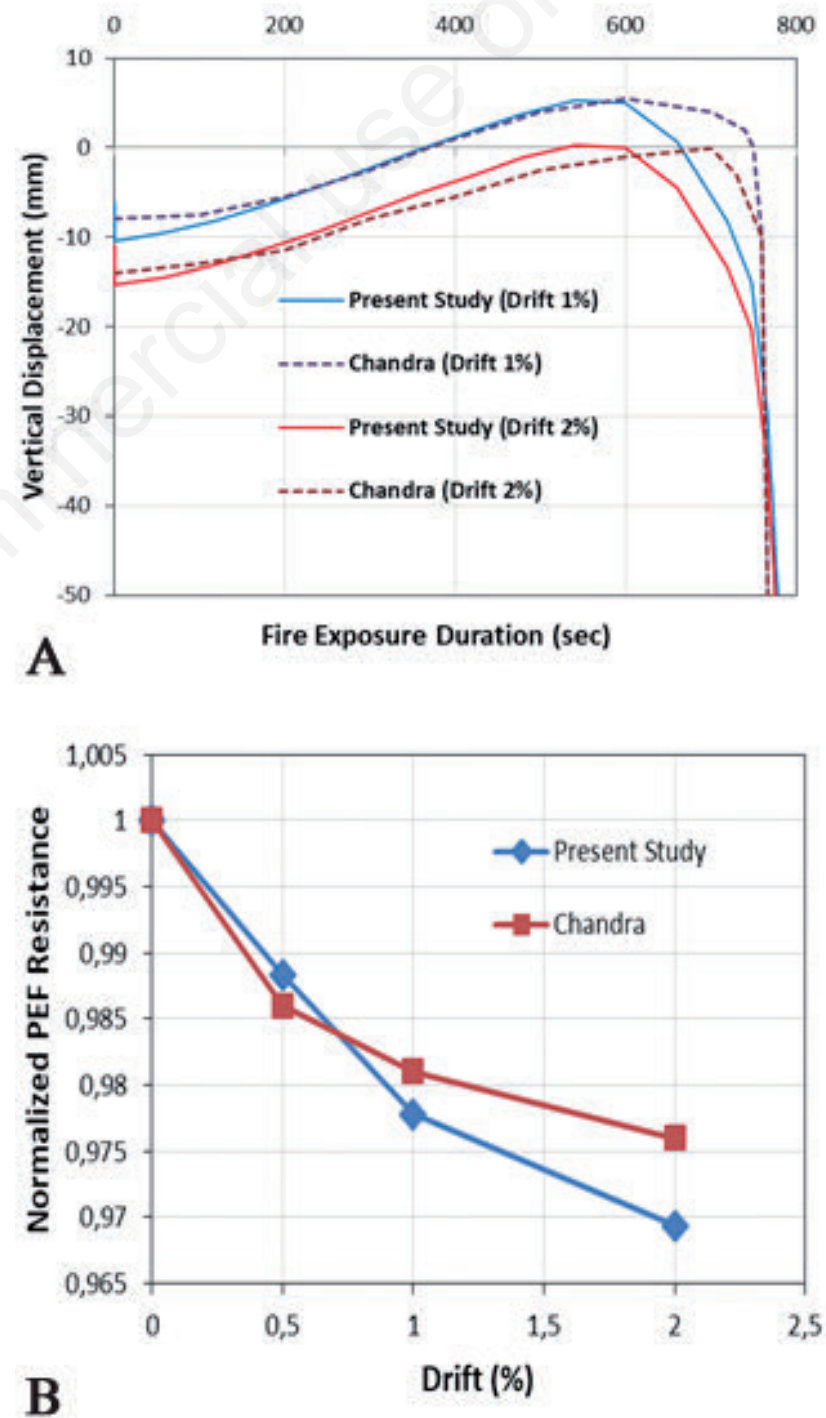

Figure 6. Comparison in PEF of present study $v$ s Chandra's. A) Vertical displacement vs Fire duration. B) Variation of normalized PEF Resistance with performance level. 
aged frame with the earthquake performance level for the frame is shown in Figure 6B.

For the case of the vertical deformation of the beam at mid-span, the results presented in Figure 6A show close similarities of curves from present study and Chandra's for both drifts. For the case of the variation of normalized PEF resistance with storey drift, both curves show a sharp decrease in the resistance before $1 \%$ storey drift ending by a small discrepancy of about $6 \%$ at a storey drift of $2 \%$.

\section{Case study: model description}

\section{Model description}

The building considered in this study is erected in the city of Chlef, Algeria, known for its high seismicity. Its structural resistant

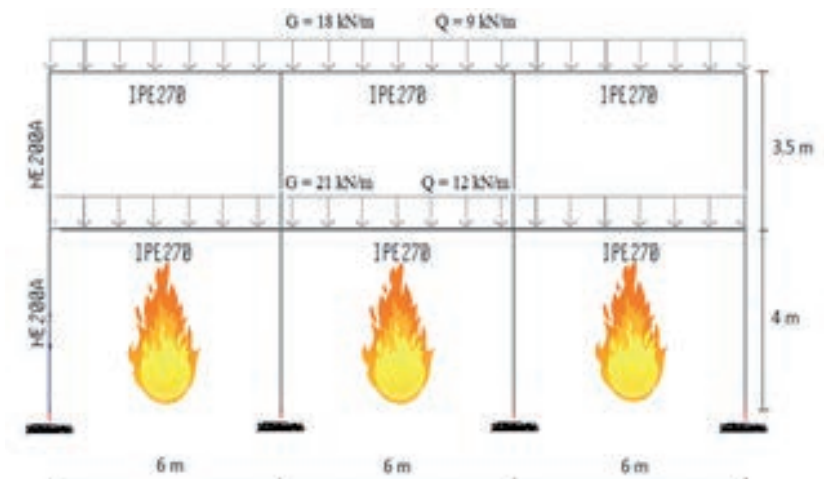

A

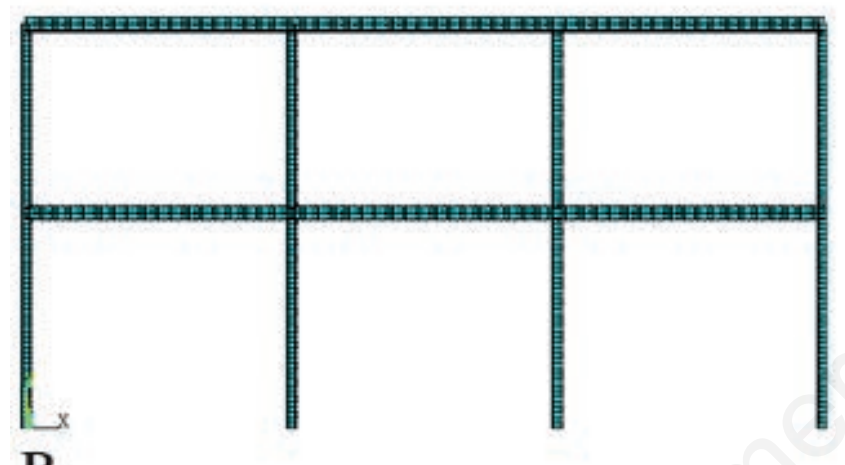

B

Figure 7. Steel portal frame. A) Frame characteristics and fire scenario. B) Numerical model.

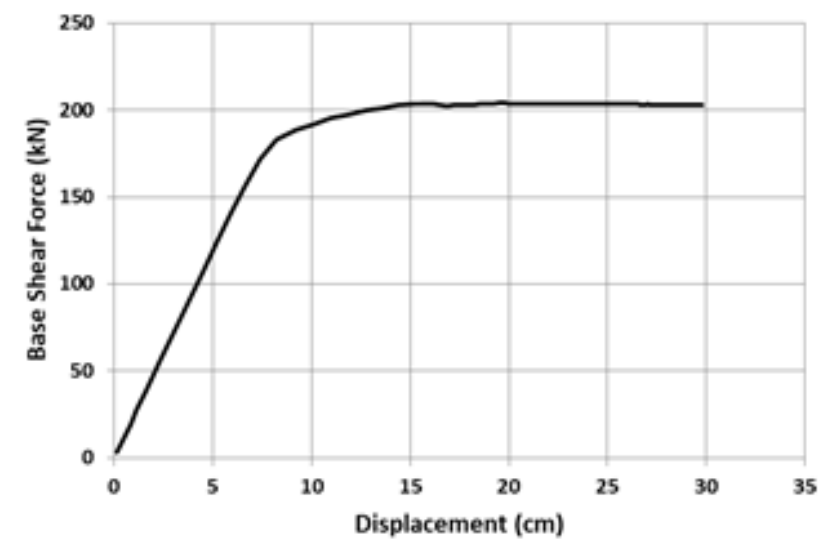

Figure 8. Pushover Curve of the steel portal frame.

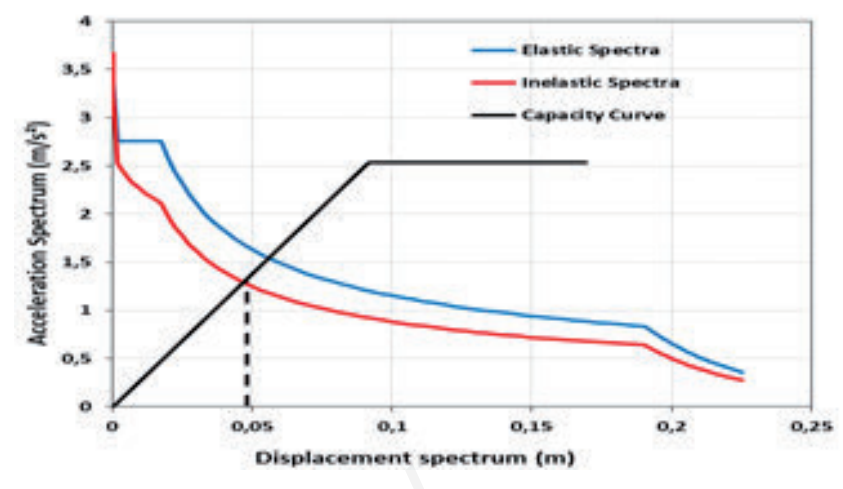

Figure 9. Seismic demand vs Capacity curve.

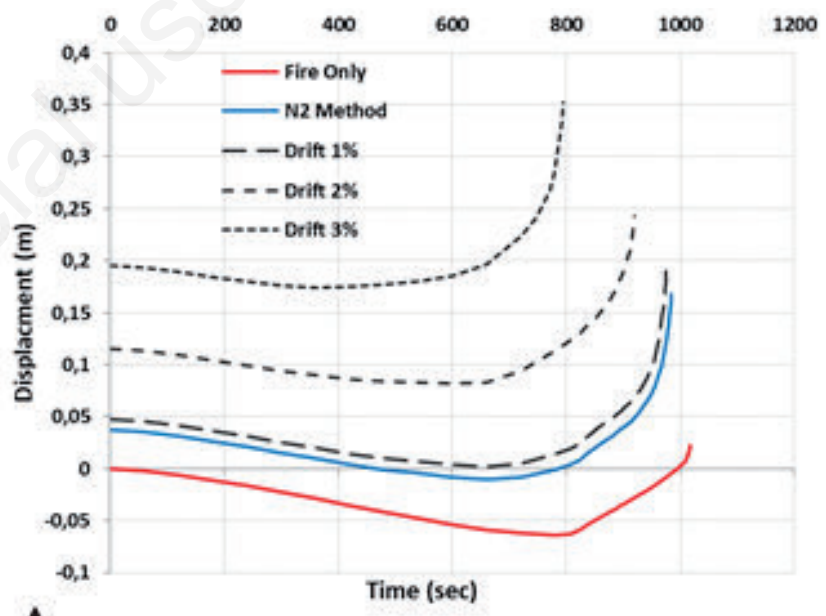

A

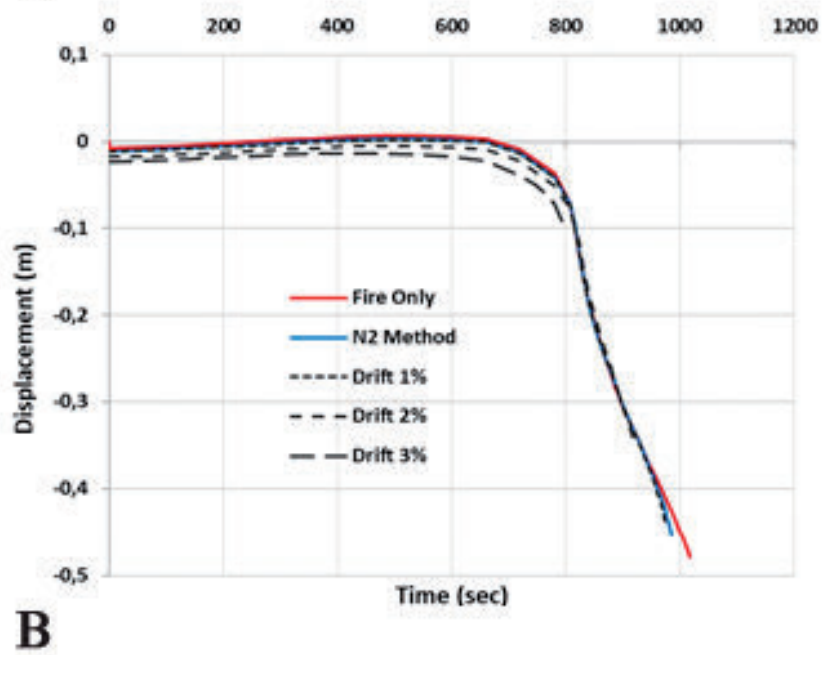

Figure 10. Displacement-time characteristics. (A) 1st Floor horizontal displacement. (B) 1st Floor vertical displacement. 
frames are 3-bays and 2-storey portal steel structures. The typical frame of the building, fire scenario and the loading applied is illustrated in Figure 7A. The size of the beam finite elements is equal to $0.1 \mathrm{~m}$ for all the columns and the beams. The numerical model and the mesh that is adopted are presented in Figure 7B. The cross-section of the finite element used for the numerical modelling, is a user-defined solid numerically integrated.

For this study, the performance point of the structure is given by, the N2 method and three other performance levels, storey drift $1 \%, 2 \%$ and $3 \%$ respectively.

In the analysis, the fire load is applied on the structure for both damaged and undamaged frames using the effect of ISO834. In case one the undamaged structure is exposed to the fire load (FIRE), while in case two, the deformed structure is exposed to the fire load (PEF). In both cases, when gravity loads are alone or when gravity and earthquake loads are associated, the fire is applied as a subsequent load.

\section{Results and Discussion}

The structure responded to the seismic motion in the elastic range, experiencing maximum storey drift of $0.8 \%$ due to the Algerian Seismic Code, RPA99v2003, ${ }^{8}$ is slightly larger than the $0.7 \%$ limit corresponding to Immediate Occupancy performance level according to the informative classification given by FEMA356. ${ }^{7}$ This means that the structure represents a minor local yielding at few places and no fractures.

Figure 8 illustrates the results of the Pushover curve. Figure 9 shows the performance point of the portal frame, obtained with N2 method according to the Eurocode $8 .{ }^{5}$

Figure 10A shows the response of both undamaged frame (FIRE) and damaged frame (PEF) for the performance level corresponding to N2 Method and the three other performance levels considered $1 \%$, $2 \%$ and $3 \%$ storey drift, under ISO fire, in terms of horizontal displacement-time characteristics in the first floor. Figure $10 \mathrm{~B}$ illustrates the evolution of the vertical displacement at the beam midpoint at the first floor of the damaged and undamaged frame.

The collapse time for the PEF in the case of the N2 method is around 16.20 minutes; it increases to about 17 minutes when submitted to fire only (FIRE), which signifies a $5 \%$ reduction in the fire resistance. For the other cases of performance level in the PEF, whenever the storey drift is important, the displacement increases.

Figure 11 schematically show the deflected shape of the frames in two cases, the case of FIRE and the case of the PEF for the N2 method performance point.

Figure 11 reveals that, while the maximum vertical displacement at half span is in the middle bay for the case of undamaged structure (Figure 11A), it has shifted to third span of the outer bay for the case of the damaged structure (Figure 11B). The latter case has produced higher vertical displace- ment and favours a sway mechanism outward of the frame.

Figure 12 shows the variation of normalized fire resistance which means the ratio of the PEF fire resistance corresponding to a given performance level (drift) to the fire resistance of undamaged frame with the earthquake.

The post-earthquake fire resistance

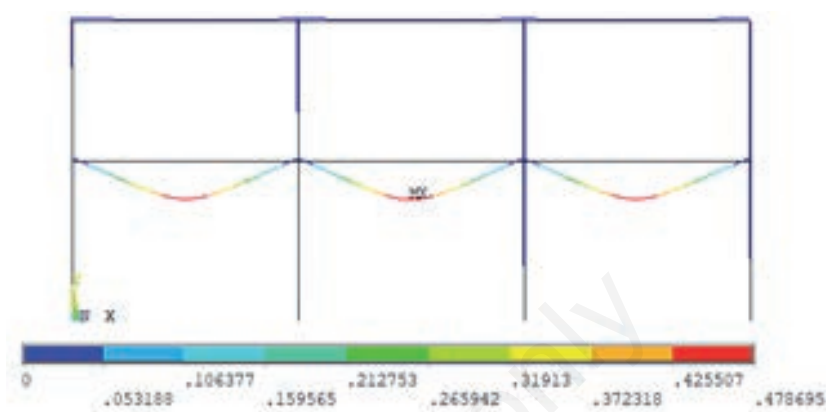

A

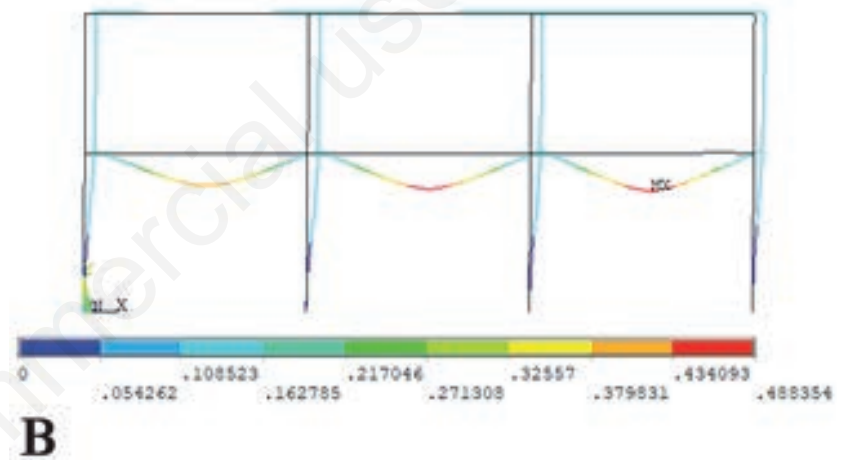

Figure 11. Deformed shape mode. (A) Undamaged structure. (B) Damaged structure.

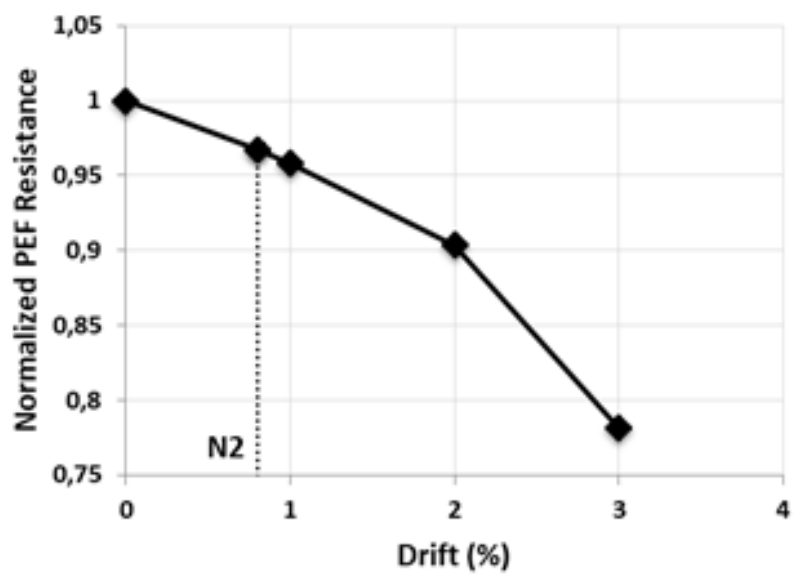

Figure 12. Variation of normalized PEF Resistance $v$ s Storey drifts of the steel portal frame. 
decreases with the increase in the earthquake damage. The difference in fire resistance is about $3.3 \%$ for the N2 Method, $4.2 \%$ for the storey drift of $1 \%, 9.6 \%$ for the storey drift of $2 \%$ and $21.9 \%$ for the storey drift of $3 \%$.

\section{Conclusions}

In this study, finite element models were used to predict the behavior of steel portal frames in PEF condition. The results presented in this study show that the horizontal displacements given by the PEF analysis are significant different when compared to the fire analysis of an undamaged structure, unlike the vertical displacements. For the PEF loading, it is important to consider the maximum displacement values which depend on the damage level. The later is induced in the structural system due to the residual displacement field after an earthquake, producing results with a difference between $3.3 \%$ and $21.9 \%$ in fire resistance situation for different performance levels.

\section{References}

1. Petrina T. Post-Earthquake Fire Tests Part 1: Report. IOP Conf Ser: Earth Environ Sci 2016;44:022011.
2. Łukomski M, Turkowski P, Roszkowski $\mathrm{P}$, Papis B. Fire resistance of unprotected steel beams - comparison between fire tests and calculation models. Proced Engineer 2017;172:665-72.

3. Lamri B, Mesquita L, Kada A, Piloto P. Behavior of cellular beams protected with intumescent coatings. Fire Res 2017;1:27.

4. Zaharia R, Pintea D. Fire after earthquake analysis of steel moment resisting frames. Int J Steel Struct 2009;9: 275-84.

5. CEN-EN 1998-1. Eurocode 8: Design of structures for earthquake resistance. Part 1: General rules, seismic actions and rules for buildings. Brussels: European Committee for Standardization; 2002.

6. Behnam B, Ronagh HR. PostEarthquake Fire performance-based behavior of unprotected moment resisting 2D steel frames. KSCE J Civil Engineer 2015;19:274-84.

7. FEMA356. Prestandard and commentary for the seismic rehabilitation of buildings rehabilitation requirements. Washington, DC: American Society of Civil Engineers; 2000.

8. RPA99v2003. Règles Parasismiques Algériennes 99 version 2003. Algérie: Centre National De Recherche Appliquée En Génie Parasismique; 2003.

9. Merouani MR, Lamri B, Kada A. Etude post-sismique des structures métalliques sous l'effet d'un incendie. 2ème Conférence Internationale de Construction Métallique et Mixte (CICOMM'2018); USTHB, Algiers, Algeria; 2018. pp 169-174.

10. Kada A, Lamri B. Numerical analysis of non-restrained long-span steel beams at high temperatures due to fire. Asian J Civil Engineer 2019;20:261-7.

11. ANSYS Academic Research. Release 16.2. Canonsburg: ANSYS; 2011.

12. CEN-EN 1991-1-2. Eurocode 1: Actions on structures - Part 1-2: General rules - Actions on structures exposed to fire. Brussels: European Committee for Standardization; 2002.

13. CEN-EN 1993-1-2. Eurocode 3: Design of steel structures - Part 1-2: General rules - Structural fire design. Brussels: European Committee for Standardization; 2005.

14. Chandra A, Bhowmick AK, Bagchi A. STR-866: non linear finite element model for Post-Earthquake Fire Performance evaluation of steel portal frames. Resilient Infrastructure; 2016. Available from: https://www.semanticscholar.org/paper/STR-866\%3A-NONL IN E A R - F IN I T E - E LEMEN TMODEL - F OR - F IR E - C h andraBhowmick/95fdec4fbed7eebd36993039 7a15344760514b46 